\title{
Challenges with heparin-based anticoagulation during cardiopulmonary bypass in children: Impact of low antithrombin activity
}

Cedric Manlhiot, PhD, ${ }^{a}$ Colleen E. Gruenwald, MHSc, CCP, PhD, ${ }^{a}$ Helen M. Holtby, MB, BS, ${ }^{a}$ Leonardo R. Brandão, MSc, MD, ${ }^{\mathrm{b}}$ Anthony K. Chan, MD, ${ }^{\mathrm{c}}$ Glen S. Van Arsdell, MD, and Brian W. McCrindle, MPH, MD

\begin{abstract}
Background: Antithrombin is one of the main natural coagulation system inhibitors. It is potentiated by heparin, and may be a key component of heparin response, particularly in infants aged $<1$ year. We sought to determine the impact of baseline antithrombin activity on response to heparin and thrombin generation during cardiopulmonary bypass (CPB).
\end{abstract}

Methods: Secondary analysis was performed using linear regression analyses, which combined patients from a trial of individualized versus weight-based heparin management for 90 infants aged $<1$ year undergoing cardiac surgery.

Results: Mean baseline antithrombin activity was $0.69 \pm 0.16 \mathrm{U} / \mathrm{mL}$, and it was lower in neonates than in older infants $(0.57 \pm 0.15$ vs $0.77 \pm 0.12 \mathrm{U} / \mathrm{mL}$; $P<.001)$. Lower baseline antithrombin activity was associated with lower postheparin anti-Xa activity (EST [SE]: $+0.47(0.19) \mathrm{U} / \mathrm{mL}$ per $100 \mathrm{U} / \mathrm{kg}$ heparin; $P=.01)$ and higher heparin doses during surgery (EST [SE]: $+51(17) \mathrm{U} / \mathrm{kg}$ per hour; $P=.003$ ). The administration of fresh frozen plasma attenuated the effect of low baseline antithrombin activity (interaction $P$ value $=.009$ ). Patients with lower anti-Xa activity recorded during $\mathrm{CPB}$ had higher levels of thrombinantithrombin complex (EST [SE]: $+12.8(4.7) \mathrm{ng} / \mathrm{mL}$ per $-1 \mathrm{U} / \mathrm{mL}$ anti-Xa; $P=.006)$; prothrombin activation fragment 1.2 (EST $[\mathrm{SE}]:+0.13(0.07)$ $\log \mathrm{pg} / \mathrm{mL}$ per $-1 \mathrm{U} / \mathrm{mL}$ anti-Xa; $P=.06$ ); and D-dimer (EST [SE]: -0.25 (0.09) $\log \mathrm{ng} / \mathrm{mL}$ per $-1 \mathrm{U} / \mathrm{mL}$ anti-Xa; $P=.009$ ) in the postoperative period after adjustment for baseline antithrombin activity, duration of CPB, amount of fresh frozen plasma and heparin used throughout surgery in multivariable models.

Conclusions: Low circulating antithrombin activity is associated with lower heparin efficacy, which ultimately leads to a lower ability to suppress thrombin generation during CPB. Determination of risk factors for heparin resistance, and potentially, antithrombin replacement therapy, may individualize and improve anticoagulation treatment. (J Thorac Cardiovasc Surg 2016;151:444-50)

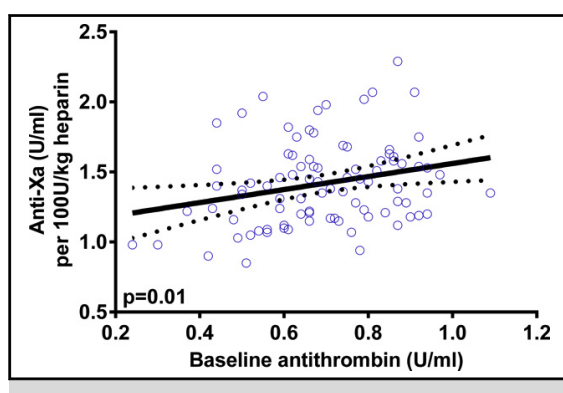

Low preoperative blood antithrombin activity is associated with decreased heparin response.

\section{Central Message}

Low blood antithrombin is associated with lower heparin efficacy and a lower ability to suppress thrombin generation during neonatal cardiac surgery.

\section{Perspective}

Low preoperative blood antithrombin activity in neonatal cardiac surgery was associated with decreased heparin efficacy and increased thrombin generation. Strategies to normalize blood antithrombin levels before heparinization should be investigated further. In the meantime, intraoperative anticoagulation dosing should be adjusted to reflect preoperative blood antithrombin levels.

See Editorial page 305.
Anticoagulation using heparin is challenging in children, particularly in infants, yet it is necessary in many clinical situations. ${ }^{1,2}$ Challenges associated with heparin

From the ${ }^{\mathrm{a}}$ Labatt Family Heart Centre, Department of Pediatrics; ${ }^{\mathrm{b}}$ Division of Haematology/Oncology, Department of Pediatrics, University of Toronto, The Hospital for Sick Children, Toronto; and ' Division of Pediatric Hematology/ Oncology, Department of Pediatrics, McMaster University, McMaster Children's Hospital, Hamilton, Ontario, Canada.

Funding for the original trial was provided by the Heart and Stroke Foundation of Ontario, Canada (NA5917).

Read at the American Heart Association Scientific Sessions, Chicago, Illinois, November 16-19, 2014. therapy in children are multifactorial but include altered pharmacodynamics and greater between-patient variability. There is a lower dose response and increased rate of

Received for publication July 1, 2015; revisions received Sept 24, 2015; accepted for publication Oct 1, 2015; available ahead of print Nov 6, 2015.

Address for reprints: Brian W. McCrindle, MPH, MD, The Hospital for Sick Children, 555 University Ave, Toronto, Ontario, Canada M5G 1X8 (E-mail: brian. mccrindle@sickkids.ca). $0022-5223 / \$ 36.00$

Copyright (C) 2016 by The American Association for Thoracic Surgery http://dx.doi.org/10.1016/j.jtcvs.2015.10.003 


\section{Abbreviations and Acronyms \\ $\mathrm{CPB}=$ cardiopulmonary bypass \\ $\mathrm{EST}=$ parameter estimate \\ $\mathrm{FFP}=$ fresh frozen plasma}

Scanning this QR code will take you to the article title page.

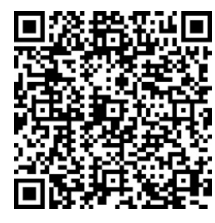

clearance than in adults resulting in decreased effectiveness in preventing thrombin generation. ${ }^{3,4}$ Heparin is used throughout cardiopulmonary bypass (CPB) to counteract the physiologic response to $\mathrm{CPB}$ and mitigate the risk of thrombosis. Improving heparin-based anticoagulation is particularly important in children who have heart disease, who often require multiple surgical interventions at a very young age and are at high risk of postoperative thrombosis ${ }^{5-10}$ and bleeding complications, ${ }^{1,11-13}$ partially owing to physiologic and maturational differences that exacerbate the adverse effects of CPB. A previous retrospective review of children undergoing cardiac surgery noted an $11 \%$ prevalence of postoperative thrombosis, and a $12 \%$ prevalence of postoperative bleeding complications $(>25 \%$ for both in children aged $<1$ year; $<2 \%$ in children age $>10$ years). ${ }^{10}$

One of the reasons for the differences in heparin sensitivity between patients (and between children and adults) may be related to the anticoagulation activity of antithrombin which is potentiated by heparin. ${ }^{14}$ Heparin covalently bonds to antithrombin and induces a conformational change in the protein structure that profoundly increases the anticoagulant activity. ${ }^{15}$ The activity of antithrombin is highly variable and can be influenced by age, inflammation, heart failure, and liver dysfunction. ${ }^{5,16,17}$ We sought to determine the effect of low preoperative antithrombin activity on the response to heparin and anticoagulant effectiveness in infants age $<1$ year undergoing cardiac surgery with $\mathrm{CPB}$. Our secondary objective was to determine the association between anticoagulation effectiveness, as reflected by the anti-Xa associated with heparin, and thrombin generation and fibrin-degradation byproduct activity after surgery.

\section{METHODS}

A secondary analysis was performed of data derived from a controlled trial of 90 patients who were randomized to weight-based versus individualized management of heparin and protamine dosing in children aged $<1$ year undergoing cardiac surgery with $\mathrm{CPB} .{ }^{18}$ Complete methods and results of the trial have been published, ${ }^{18}$ and relevant methodologic considerations are addressed later. In short, we showed that individualized heparin and protamine dosing using the Hepcon HMS Plus Hemostatis Management System (HMS; Medtronic, Minneapolis, Minn), with a locally developed pediatric-specific algorithm, was associated with improved surgical outcomes, compared with patients receiving heparin on a weight-based dosing algorithm with periodic monitoring. Patients receiving individualized heparin and protamine dosing had more-stable anticoagulation activity throughout $\mathrm{CPB}$; reduced postoperative activity of thrombin-antithrombin complex and prothrombin fragment F1.2, reduced need for blood transfusions; and reduced ventilation, intensive care unit, and hospital stay. Baseline antithrombin activity was not different between the 2 experimental groups in the original study, and no additional analyses of antithrombin association with anticoagulant and operative outcomes were included in the original publication.

All patients had to weigh $>2 \mathrm{~kg}$ at surgery and age adjusted for number of weeks of gestation at birth had to be $>36$ weeks. Patients were eligible if they had no preoperative anticoagulation exposure, no previous antithrombin replacement therapy, no major previous bleeding and/or thrombotic complications, and no history of renal and/or liver failure. Other than the heparin and protamine management, all patients were treated in the same manner with respect to perioperative and postoperative blood transfusion protocols and use of antifibrinolytic agents.

All patients had hemostasis monitoring before, during, and after surgery (blood antithrombin activity, blood hemostasis, and complete blood count). All laboratory investigations during CPB were performed every $30 \mathrm{mi}$ nutes; however, for the purpose of this study, only the last measurement on CPB was considered. Postoperative measurements were performed 24 hours after arrival at the critical care unit. All patients were monitored using the hemostasis management device (these data were not made available to physicians for patients allocated to the weight-based heparin management group). Measurements of blood antithrombin activity, blood hemostasis, complete blood counts, anti-Xa activity, and D-dimers were performed in a central clinical laboratory.

Measurements of thrombin-antithrombin complex and prothrombin fragment were used to quantify thrombin generation. Measurements were performed using the Enzygnost thrombin-antithrombin complex and prothrombin fragment monoclonal assays (Siemens, Marburg, Germany). Several metrics were used to characterize heparin efficacy including the initial anti-Xa activity achieved per $100 \mathrm{U} / \mathrm{kg}$ of heparin in the pre-CPB bolus given to each patient, and the total amount of heparin used, indexed to patient weight and duration of $\mathrm{CPB}$.

Both original study groups were combined for this secondary analysis. Data are presented as means with SDs, medians with 25th and 75th percentiles, or frequencies, as appropriate. Primary analyses were performed using linear regression models (both univariable and multivariable models), with maximum likelihood estimates for parameter estimation. Results from regression models are reported as parameter estimates (ESTs) and standard errors (SEs); ESTs represent the change in the dependent variable for each increase of 1 unit in the independent variable (if continuous) or for the presence (vs absence) of the dependent variable (if binary), as appropriate.

Given the limits of the sample size and the need for biologically relevant adjustments, we elected to use an a priori selection of covariates as part of our model-building strategy, rather than a data-driven approach, to make sure that all biologically important covariates were adjusted for, without overfitting the regression models. The strong correlation between age at surgery and antithrombin activity, along with the limited number of patients at the higher end of the age spectrum with low antithrombin activity, precluded using age at surgery as a covariate. Covariates specific to each regression model are listed at the appropriate location in the Results section.

Although no differences were found between study groups in the original trial regarding baseline antithrombin activity, patients in the HMS group had different heparin management, improved anticoagulation, decreased thrombin generation, and improved clinical outcomes. Given 
TABLE 1. Patient and surgery characteristics

\begin{tabular}{lc}
\multicolumn{1}{c}{ Characteristics } & Value \\
\hline Patients & \\
Age at operation (d) & $103(10-191)$ \\
$\quad$ Neonate $(\leq 31)$ & $37(41)$ \\
$\quad$ Infants (32-365) & $53(59)$ \\
Gestational age at birth (wk) & $38.6 \pm 1.6$ \\
Gender, male & $51(57)$ \\
Diagnosis & \\
$\quad$ Aortic arch/trunk abnormalities & $11(12)$ \\
$\quad$ Pulmonary atresia/stenosis with intact ventricular & $7(8)$ \\
$\quad$ septum & \\
$\quad$ Septal defects & $16(18)$ \\
Single ventricle (6 Norwood, 3 cavopulmonary & $9(10)$ \\
$\quad$ shunts) & $19(21)$ \\
Tetralogy of Fallot & $28(31)$ \\
Transposition of the great arteries/double outlet & \\
$\quad$ right ventricle & \\
Surgery & \\
Weight at surgery (kg) & $5.0 \pm 1.8$ \\
Surgery Aristotle score & $9.5 \pm 2.0$ \\
Cardiopulmonary bypass time (min) & $109 \pm 39$ \\
Crossclamp time (min) & $72 \pm 29$ \\
Use of deep hypothermic circulatory arrest & $12(13)$ \\
Preoperative steroids & $34(38)$ \\
Aprotinin (vs tranexamic acid) & $14(16)$ \\
Vasopressin & $12(13)$ \\
\hline
\end{tabular}

Values are mean $\pm \mathrm{SD}, \mathrm{n}(\%)$, or medians with 25 th and 75 th percentiles.

that the associations between preoperative antithrombin activity and many of those factors are considered in this study, we performed a sensitivity analysis, adjusting for original group assignment in the various regression models, to test whether group assignment would in any way confound the associations reported in this study. As no such confounding was observed, we elected not to report these additional analyses. All statistical analyses were performed using SAS statistical software, version 9.3 (SAS Institute, Cary, NC).

The study was approved by the Research Ethics Board of the Hospital for Sick Children; informed consent was obtained from a legal guardian for all enrolled patients. Authors had full access to all study data, performed the analysis, and take responsibility for the accuracy and content of the article.

\section{RESULTS}

A total of 90 patients were included, median age at surgery was 15 weeks (interquartile range: 10 days to 6 months), with 37 (41\%) patients aged $<1$ month. Patient and operation characteristics are shown in Table 1. Mean baseline antithrombin activity was $0.69 \pm 0.16 \mathrm{U} / \mathrm{mL}$. Baseline antithrombin activity had a strong positive association with age at the time of the procedure (Figure 1), with neonates having lower activity than older infants $(0.57 \pm 0.15$ vs $0.77 \pm 0.12 \mathrm{U} / \mathrm{mL})$. Similar results were noted when age at procedure was adjusted for gestational age (mean: $39 \pm 2$ weeks).

Factors associated with preoperative blood antithrombin activity assessed in a multivariable linear regression model are listed in Table 2. Factors associated with lower

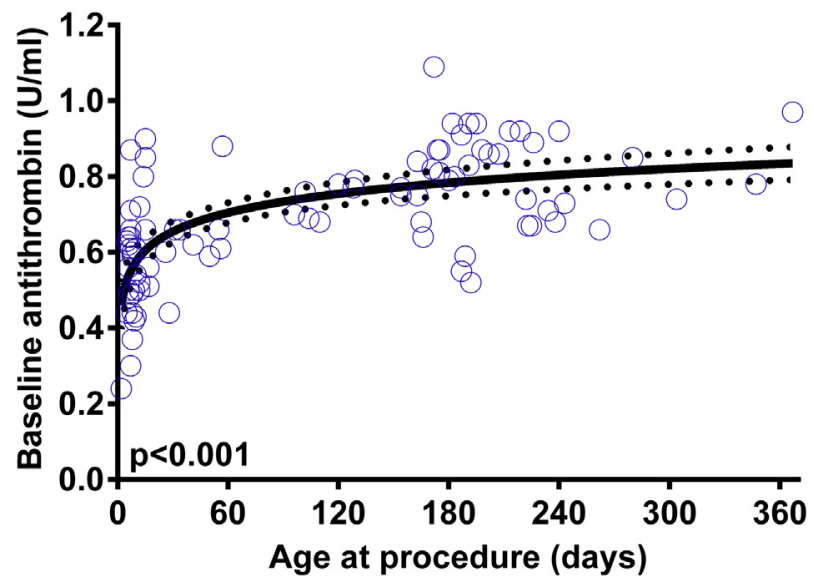

FIGURE 1. Antithrombin activity by age at surgery. Blue circles represent individual patient values; solid lines show the estimates from regression models; and dotted lines show the $95 \%$ confidence interval.

preoperative antithrombin activity included the following: younger age at operation; blood type group other than type $\mathrm{O}$; higher preoperative international normalized ratio; and diagnosis of hypoplastic left heart syndrome. On the other hand, patients with tetralogy of Fallot had higher blood antithrombin activity.

Patients received an average initial heparin bolus of $346 \pm 69 \mathrm{U} / \mathrm{kg}$. Lower baseline antithrombin activity was associated with lower postheparin anti-Xa activity achieved per $100 \mathrm{U} / \mathrm{kg}$ of heparin (EST [SE]: +0.47 [0.19] U/mL per $100 \mathrm{U} / \mathrm{kg}$ heparin; $P=.01$ ) (Figure 2). After the initial heparin bolus, 47 patients $(52 \%)$ were deemed to have an insufficient level of anticoagulation activity (either lower than the targeted activated clotting time values or the targeted blood heparin concentration, as measured by the HMS); they received an additional mean heparin dose of $125 \pm 71 \mathrm{U} / \mathrm{kg}$. The amount of heparin given during CPB varied considerably: total heparin given was $601 \pm 274$ $\mathrm{U} / \mathrm{kg}$ per hour of $\mathrm{CPB}$, including heparin in to the prime.

TABLE 2. Factors associated with lower preoperative blood antithrombin activity assessed in a multivariable linear regression model with percentage reliability in bootstrap bagging resampling (500 resamples)

\begin{tabular}{|c|c|c|c|}
\hline Patients & $\begin{array}{c}\text { Reliability } \\
(\%)\end{array}$ & $\begin{array}{l}\text { EST (SE) in IU/mL } \\
\text { antithrombin }\end{array}$ & $\begin{array}{c}P \\
\text { value }\end{array}$ \\
\hline Age at operation (d) & 95 & & \\
\hline$\leq 31$ & & $-0.107(0.033)$ & .001 \\
\hline $32-90$ & & $-0.095(0.044)$ & .03 \\
\hline $91-365$ & & Reference & \\
\hline Blood group other than type $\mathrm{O}$ & 71 & $-0.062(0.024)$ & .01 \\
\hline Higher preoperative INR & 98 & $-0.028(0.081)$ & .001 \\
\hline $\begin{array}{l}\text { Diagnosis of hypoplastic } \\
\text { left heart syndrome }\end{array}$ & 86 & $-0.147(0.048)$ & .003 \\
\hline $\begin{array}{r}\text { Diagnosis other than } \\
\text { tetralogy of Fallot }\end{array}$ & 62 & $-0.063(0.036)$ & .04 \\
\hline
\end{tabular}



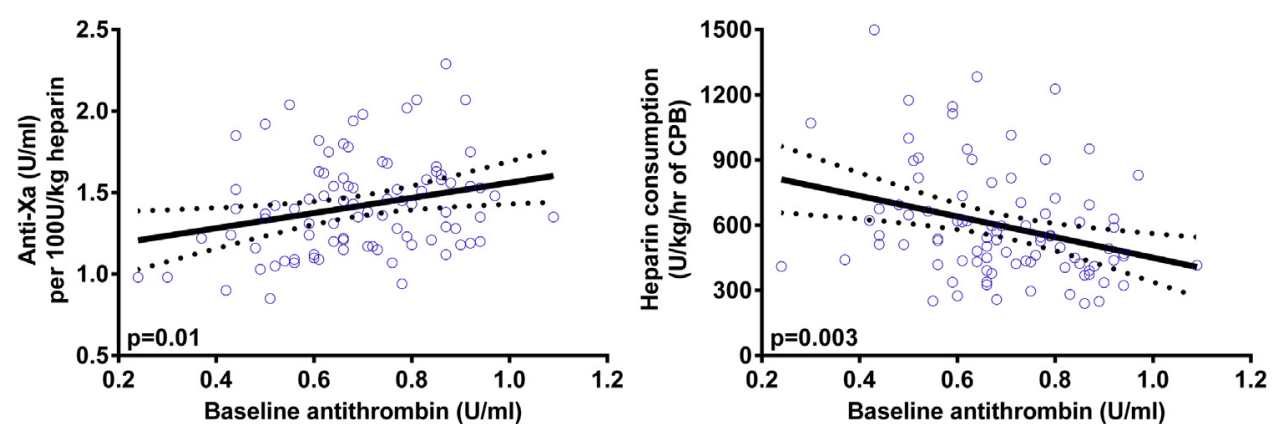

FIGURE 2. Association between preoperative blood antithrombin activity and (left) heparin response (anti-Xa achieved after initial heparin bolus per $100 \mathrm{U} / \mathrm{kg}$ of heparin), and heparin dose (heparin used throughout CPB, indexed for patient weight and duration of cardiopulmonary support) (right). Blue circles represent individual patient values; solid lines show the estimates from regression models; and dotted lines show the $95 \%$ confidence interval. $C P B$, Cardiopulmonary bypass.

Lower baseline antithrombin activity was associated with more heparin being given (EST [SE]: +51 [17] U/kg per hour, for a diminution of $0.1 \mathrm{U} / \mathrm{mL}$ in baseline antithrombin; $P=.003$ ) (Figure 2). The effect was greater in neonates (EST [SE]: -39 [18] U/kg per hour) than older infants (EST [SE]: -22 [24] U/kg per hour) (interaction $P$ value $=.003$ ). All patients received fresh frozen plasma (FFP) in the prime or during surgery, as per clinical protocol, at an average volume of $62 \pm 38 \mathrm{~mL} / \mathrm{kg}$. The administration of FFP was associated with attenuation of the effect of antithrombin activity on total heparin given during CPB (EST [SE]: -57 [17] U/kg per hour if $<40 \mathrm{~mL} / \mathrm{kg}$ FFP; -50 [17] U/kg per hour if $40-64 \mathrm{~mL} / \mathrm{kg}$ FFP; and -42 [18] U/kg per hour, if $\geq 65 \mathrm{~mL} / \mathrm{kg}$ FFP [interaction $P$ value $=.009$ ]).

In linear regression models, after adjusting for heparin given, lower baseline antithrombin activity was associated with lower minimum anti-Xa activity throughout $\mathrm{CPB}$, and lower anti-Xa at the end of CPB (Figure 3). In both cases, model fit as measured by model quasi-likelihood information criterion improved in regression models, including baseline antithrombin activity, in addition to heparin given alone. Patients with a lower minimum anti-Xa level during CPB had higher activity of thrombin- antithrombin complex (EST [SE]: +12.8 (4.7) ng/mL per $-1 \mathrm{U} / \mathrm{mL}$ anti-Xa; $P=.006$ ); prothrombin activation fragment 1.2 (EST [SE]: +0.13 [0.07] $\log \mathrm{pg} / \mathrm{mL}$ per $-1 \mathrm{U} / \mathrm{mL}$ anti-Xa; $P=.06$ ); and D-dimer (EST [SE]: -0.25 [0.09] log $\mathrm{ng} / \mathrm{mL}$ per $-1 \mathrm{U} / \mathrm{mL}$ anti-Xa; $P=.009)$ in the postoperative period after adjustment in multivariable models for baseline antithrombin activity, duration of CPB, amount of FFP used throughout surgery, and heparin given throughout $\mathrm{CPB}$ (Figure 4). Longer CPB time was associated with increased levels for all markers. Lower baseline antithrombin activity was associated with increased D-dimer activity (EST [SE]: -0.084 [0.037] $\log \mathrm{ng} / \mathrm{mL}$ for a reduction of $0.1 \mathrm{U} / \mathrm{mL}$ in baseline antithrombin; $P=.03$ ). Heparin given (either unadjusted or adjusted for baseline antithrombin activity) and volume of FFP transfusion were not associated with any of these markers.

\section{DISCUSSION}

This study investigated the effects of circulating plasma antithrombin activity before cardiac surgery with $\mathrm{CPB}$ on heparin response, amount given, and effectiveness in children aged $<1$ year. We noted important variations in baseline plasma antithrombin activity that were only partially explained by age at operation. Low plasma
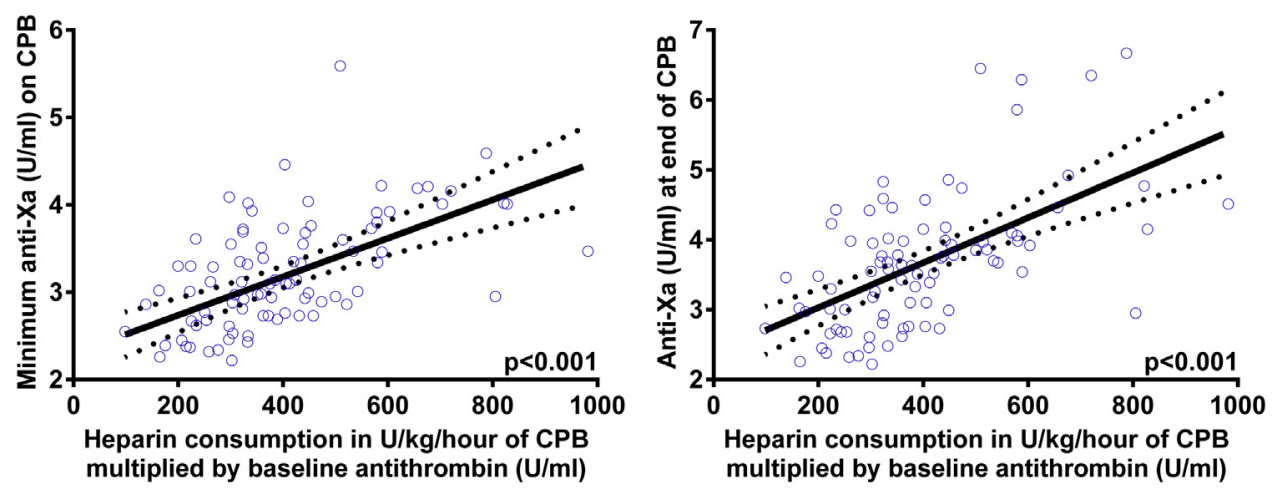

FIGURE 3. Association between heparin dose throughout CPB indexed to (left) baseline antithrombin and minimum anti-Xa activity achieved throughout surgery, and (right) anti-Xa activity at the end of surgery. Blue circles represent individual patient values; solid lines show the estimates from regression models; and dotted lines show the $95 \%$ confidence interval. $C P B$, Cardiopulmonary bypass. 

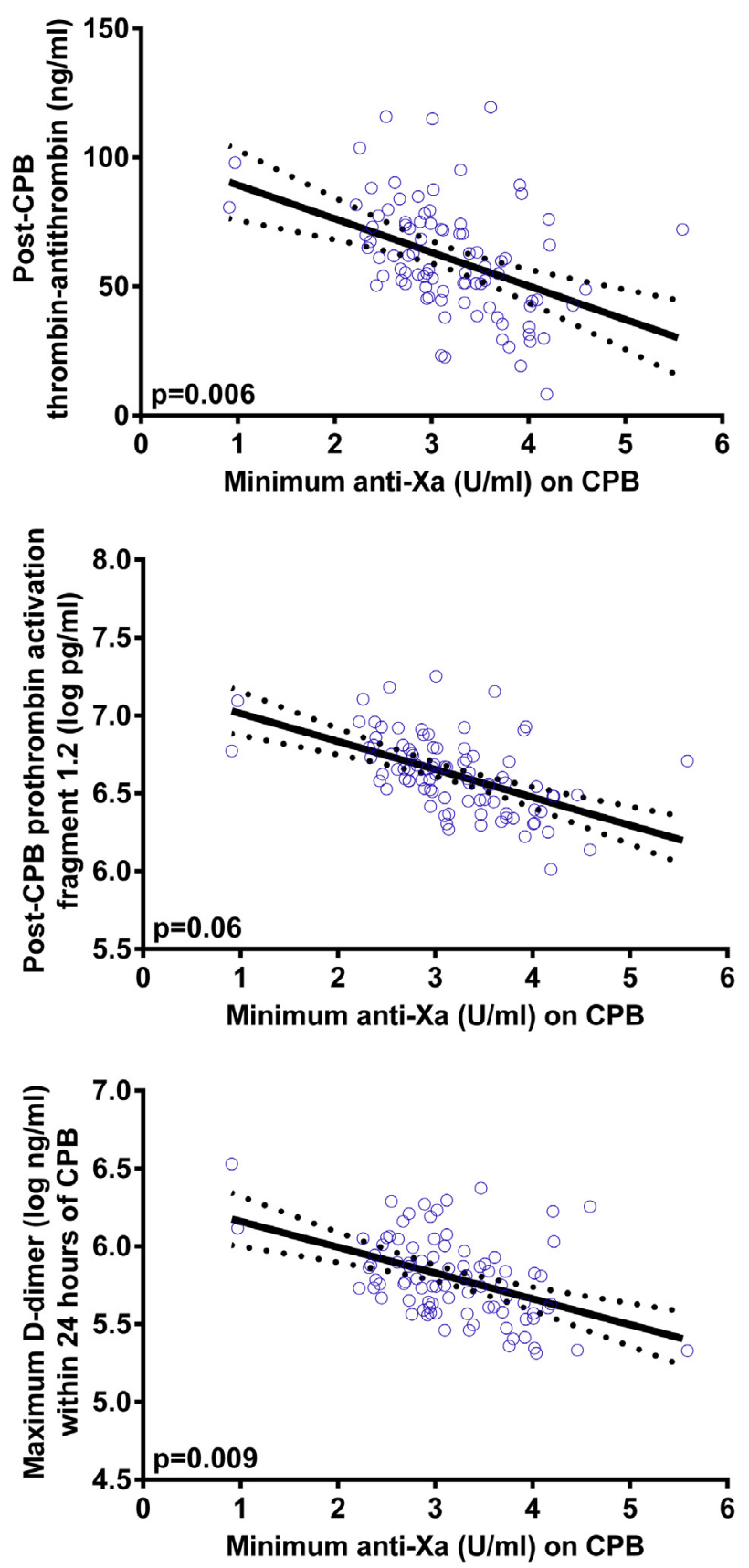

FIGURE 4. Association between minimum anti-Xa activity achieved during the operation and thrombin generation post-CPB, as measured by thrombin-antithrombin complexes, prothrombin fragment 1.2 , and maximum D-dimer measured 24 hours after CPB. Blue circles represent individual patient values; solid lines show the estimates from regression models; and dotted lines show the $95 \%$ confidence interval. $C P B$, Cardiopulmonary bypass.

antithrombin activity was associated with impaired response to heparin, increased frequency of heparin being given, and a lower level of anticoagulation through $\mathrm{CPB}$, as measured by plasma anti-Xa activity. Lower anticoagulation activity was associated with increased thrombin and fibrin generation. The use of FFP in these patients attenuated, but did not correct, the deleterious effect of low antithrombin-circulating activity on anticoagulation.

Children are born with an immature coagulation system, including blood antithrombin activity. ${ }^{16}$ Activity of coagulation factors normalizes asynchronously over the first few years of life $16,19,20$; however, previous studies have shown delayed normalization in children who have congenital heart disease, ${ }^{11}$ particularly those with single-ventricle physiology. ${ }^{21,22}$ In patients with single ventricles, these abnormalities have been associated with increased risk of thrombosis. ${ }^{21,22}$ The evidence regarding the clinical relevance of these abnormalities in patients with 2 ventricles remains equivocal, ${ }^{23,24}$ although results presented here support an effect of antithrombin on anticoagulation and hemostatic complications throughout the population of patients who have congenital heart disease.

Age was only one contributor to low antithrombin activity. In addition to maturational changes, other factors are associated with coagulation system abnormalities (including low antithrombin activity) in patients with congenital heart disease, many of which are associated with the physiological effects of cardiac insufficiency. These include coagulation factor consumption secondary to inflammation and activation of the coagulation system ${ }^{25}$ and decreased coagulation factor production by the liver. ${ }^{26}$ Together, these factors explain, at least partially, the low activity of preoperative antithrombin observed in patients who have congenital heart disease, in this and other studies.

Achieving optimal anticoagulation on CPB requires a balance between the inhibition of thrombin generation and the activation of platelets, while avoiding bleeding complications. In infants, this balance has proven to be particularly challenging to achieve, as evidenced by the high rate of postoperative bleeding and thrombotic complications. ${ }^{10}$ Our results demonstrate that low antithrombin activity is a factor in the variability of the response to heparin, and in the degree of activation of the coagulation system. Antithrombin plays a critical role in this process as the primary biological target of heparin. Variations in antithrombin activity were not completely explained by age. Coagulation-factor production can be impaired in various circumstances, particularly liver dysfunction and inflammatory illness. ${ }^{3,17}$ Children with unrepaired congenital heart disease often have both elevated inflammatory markers and liver dysfunction. Future research might focus on identifying the determinants of antithrombin activity in children with congenital heart disease. $^{9}$

Properly measuring anticoagulation effectiveness is a challenge that complicates the achievement of optimal surgical outcomes. Four strategies are routinely employed to monitor anticoagulation during CPB: point-of-care clotting assays (activated clotting time); 
global hemostatic assay (eg, thromboelastography), indirect heparin concentration assay (eg, with the HMS device); or direct measurement of anti-Xa activity and/or thrombin generation. ${ }^{27}$ Direct measurement of anti-Xa and/or thrombin generation is likely the optimal strategy from a physiologic point of view; however, those tests are not currently available at the bedside and therefore cannot be used to guide anticoagulation management during CPB. Bedside measurement of activated clotting time (ACT) has historically been the method of choice to guide anticoagulation during surgery. ${ }^{1,2,13,28}$ However, clotting time is known to be influenced by factors other than coagulation system activity, including temperature, hemodilution, choice of activator, and other medications.

Studies have shown a poor correlation between the ACT and other measures of anticoagulation, including anti-Xa activity. ${ }^{29}$ For these reasons, we focused on anti-Xa activity and markers of thrombin generation. Thromboelastography has recently been introduced in operating rooms as one of the global hemostatic assays to monitor anticoagulation and diagnose coagulopathy. Results from preliminary studies are promising, but they show an undue influence of extraneous factors that are not related to anticoagulation. ${ }^{30,31}$

The third option is to monitor anticoagulation with a bedside indirect blood heparin concentration assay, as was done in our trial. This method of managing anticoagulation during CPB still has limitations resulting from the poor correlation between plasma heparin concentration (anti-Xa) and anticoagulation activity (particularly in the context of low blood antithrombin activity), but it is likely superior to basic clotting time, as demonstrated in other studies. ${ }^{6,18,28}$

One of the main drawbacks of using indirect measures of heparin concentration to guide heparin management throughout procedures is the fact that, as demonstrated in this study, response to heparin varies among patients. We show that the blood activity of antithrombin is an important factor in the response to heparin, but other factors are involved, including the heparin manufacturing process, and its potency. ${ }^{32}$ In addition, genetic variance has been found in the antithrombin protein. Antithrombin binds heparin through 4 or 5 glycosylation sites, depending on the antithrombin glycoform. Point mutations at these glycosylation sites are common, and they may impair the strength of the covalent bonding, directly affecting the anticoagulation activity of antithrombin. These mutations are now thought to be common and may explain a large proportion of betweenpatient variation in heparin response. ${ }^{15,33}$ This avenue is certainly important for further research.

The finding that quite large doses of FFP did not completely correct the deleterious effect of low plasma antithrombin activity has clinical implications: FFP has been suggested as a therapy for antithrombin deficiency. However, with an antithrombin concentration of $1 \mathrm{U} / \mathrm{mL}$ in standard FFP, the doses needed to fully rescue the phenotype are prohibitive, particularly in very young patients. ${ }^{34,35}$ The other option for correcting antithrombin deficiency is to give endogenous pooled antithrombin prior to heparinization. ${ }^{36} \mathrm{~A}$ recent study in adults who have heparin resistance and are undergoing cardiac surgery has shown increased heparin sensitivity. ${ }^{37,38}$ Use of pooled antithrombin in children is increasing, but the efficacy remains undetermined and should be tested in well designed clinical trials.

This study must be interpreted in light of some limitations. The original study was not designed to answer our primary research question, and differences in heparin and protamine management introduced by individualization in the experimental group might have introduced variation and biased the results, despite our using it as a covariate and showing no effect. Given the limited number of patients included in this study, we often were not able to derive meaningful comparisons among the various anatomic subgroups of patients. The study population is intentionally homogeneous and excludes, by design, some of the highest-risk groups (eg, premature infants, those with previous heparin exposure, those who had extracorporeal support before surgery). Future studies are needed to confirm our findings in those higher-risk populations.

The volume of FFP used, beyond the initial unit in the CPB prime, was on an as-needed basis, and therefore, confounding by indication might have biased some of the observations. Additionally, heparin use during CPB should be considered a surrogate marker of heparin clearance, as it was not a true biological measure of clearance. Finally, given the strong correlation between age at operation and antithrombin activity, the limitations of the available sample size, and the limited number of patients at the older end of the age spectrum with low antithrombin, we were not able to validly assess whether the association between antithrombin and outcome was independent of age, and/or whether age at operation affects those outcomes via an antithrombin-independent mechanism. This specific research question needs to be answered in larger studies that include children aged $>1$ year, and a sufficient number of older children who have low antithrombin activity.

\section{CONCLUSIONS}

Infants with heart disease who are about to undergo cardiac surgery were noted to have low plasma antithrombin activity preoperatively. This level of activity was associated with impaired heparin response, increased heparin doses, lower anticoagulation effectiveness, and increased thrombin generation. Further research is needed, as this therapy has a narrow therapeutic margin. Large-scale, high-quality studies aimed at identifying the determinants of heparin resistance, and best strategies to correct this problem, are needed. Antithrombin replacement 
therapy has been identified ${ }^{39}$ as a potentially important intervention strategy to correct antithrombin deficiency and individualize and improve anticoagulation; it seems a warranted next step, based on positive trials in adults and the results of this study.

\section{Conflict of Interest Statement}

Medtronic Canada provided in kind support for the original trial but had no role in any aspects of the trial or in the decision to publish this article. Authors have nothing to disclose with regard to commercial support.

\section{References}

1. Giglia TM, Massicotte MP, Tweddell JS, Barst RJ, Bauman M, Erickson CC, et al. Prevention and treatment of thrombosis in pediatric and congenital heart disease: a scientific statement from the American Heart Association. Circulation. 2013;128:2622-703.

2. Monagle P, Chan AK, Goldenberg NA, Ichord RN, Journeycake JM, Nowak-Gottl U, et al. Antithrombotic therapy in neonates and children: antithrombotic therapy and prevention of thrombosis, 9th ed: American College of Chest Physicians evidence-based clinical practice guidelines. Chest. 2012;141:e737S-801S.

3. Chan AK, Leaker M, Burrows FA, Williams WG, Gruenwald CE, Whyte L, et al. Coagulation and fibrinolytic profile of paediatric patients undergoing cardiopulmonary bypass. Thromb Haemost. 1997;77:270-7.

4. Yee DL, O'Brien SH, Young G. Pharmacokinetics and pharmacodynamics of anticoagulants in paediatric patients. Clin Pharmacokinet. 2013;52:967-80.

5. Heying R, van Oeveren W, Wilhelm S, Schumacher K, Grabitz RG, Messmer BJ, et al. Children undergoing cardiac surgery for complex cardiac defects show imbalance between pro- and anti-thrombotic activity. Crit Care. 2006;10:R165.

6. Koster AT, Fischer M, Praus H, Haberzettl WM, Kuebler R, Hetzer, et al. Hemostatic activation and inflammatory response during cardiopulmonary bypass: impact of heparin management. Anesthesiology. 2002;97:837-41.

7. Kozik DJ, Tweddell JS. Characterizing the inflammatory response to cardiopulmonary bypass in children. Ann Thorac Surg. 2006;81:S2347-54.

8. Seghaye MC. The clinical implications of the systemic inflammatory reaction related to cardiac operations in children. Cardiol Young. 2003;13:228-39.

9. McCrindle BW, Li JS, Manlhiot C, Tweddell JS, Giglia TM, Massicotte MP, et al. Challenges and priorities for research: a report from the National Heart, Lung, and Blood Institute (NHLBI)/National Institutes of Health (NIH) Working Group on thrombosis in pediatric cardiology and congenital heart disease. Circulation. 2014;130:1192-203.

10. Manlhiot C, Menjak IB, Brandao LR, Gruenwald CE, Schwartz SM, Sivarajan VB, et al. Risk, clinical features, and outcomes of thrombosis associated with pediatric cardiac surgery. Circulation. 2011;124:1511-9.

11. Odegard KC, Zurakowski D, Hornykewycz S, DiNardo JA, Castro RA, Neufeld EJ, et al. Evaluation of the coagulation system in children with two-ventricle congenital heart disease. Ann Thorac Surg. 2007;83:1797-803.

12. Williams GD, Bratton SL, Ramamoorthy C. Factors associated with blood loss and blood product transfusions: a multivariate analysis in children after open-heart surgery. Anesth Analg. 1999;89:57-64.

13. Gruenwald CE, Manlhiot C, Crawford-Lean L, Foreman C, Brandao LR, McCrindle BW, et al. Management and monitoring of anticoagulation for children undergoing cardiopulmonary bypass in cardiac surgery. J Extra Corpor Technol. 2010;42:9-19.

14. Andrew M, Monagle P, Brooker LA. Thromboembolic Complications During Infancy and Childhood. London: B.C. Decker; 2000.

15. Pol-Fachin L, Franco Becker C, Almeida Guimaraes J, Verli H. Effects of glycosylation on heparin binding and antithrombin activation by heparin. Proteins. 2011;79:2735-45.

16. Ignjatovic V, Lai C, Summerhayes R, Mathesius U, Tawfilis S, Perugini MA, et al. Age-related differences in plasma proteins: how plasma proteins change from neonates to adults. PLoS One. 2011;6:e17213.

17. Kajimoto H, Nakazawa M, Murasaki K, Mori Y, Tanoue K, Kasanuki H, et al. Increased thrombogenesity in patients with cyanotic congenital heart disease. Circ J. 2007; 71:948-53.

18. Gruenwald CE, Manlhiot C, Chan AK, Crawford-Lean L, Foreman C, Holtby HM, et al. Randomized, controlled trial of individualized heparin and protamine management in infants undergoing cardiac surgery with cardiopulmonary bypass. J Am Coll Cardiol. 2010;56:1794-802.

19. Monagle P, Barnes C, Ignjatovic V, Furmedge J, Newall F, Chan A, et al. Developmental haemostasis. Impact for clinical haemostasis laboratories. Thromb Haemost. 2006;95:362-72.

20. Andrew M, Vegh P, Johnston M, Bowker J, Ofosu F, Mitchell L. Maturation of the hemostatic system during childhood. Blood. 1992;80:1998-2005.

21. Odegard KC, McGowan FX Jr, DiNardo JA, Castro RA, Zurakowski D, Connor CM, et al. Coagulation abnormalities in patients with single-ventricle physiology precede the Fontan procedure. J Thorac Cardiovasc Surg. 2002;123:459-65.

22. Odegard KC, McGowan FX Jr, Zurakowski D, DiNardo JA, Castro RA, del Nido PJ, et al. Coagulation factor abnormalities in patients with singleventricle physiology immediately prior to the Fontan procedure. Ann Thorac Surg. 2002;73:1770-7.

23. Colon-Otero G, Gilchrist GS, Holcomb GR, Ilstrup DM, Bowie EJ. Preoperative evaluation of hemostasis in patients with congenital heart disease. Mayo Clin Proc. 1987;62:379-85.

24. Petaja J, Lundstrom U, Sairanen H, Marttinen E, Griffin JH. Central venous thrombosis after cardiac operations in children. J Thorac Cardiovasc Surg. 1996;112:883-9.

25. Levi M, van der Poll T, Buller HR. Bidirectional relation between inflammation and coagulation. Circulation. 2004;109:2698-704.

26. Moller S, Bernardi M. Interactions of the heart and the liver. Eur Heart J. 2013; 34:2804-11.

27. Oliver WC. Overview of heparin and protamine management and dosing regimens in pediatric cardiac surgical patients. Semin Cardiothorac Vasc Anesth. 2003; 7:387-410.

28. Guzzetta NA, Bajaj T, Fazlollah T, Szlam F, Wilson E, Kaiser A, et al. A comparison of heparin management strategies in infants undergoing cardiopulmonary bypass. Anesth Analg. 2008;106:419-25.

29. Gruenwald C, de Souza V, Chan AK, Andrew M. Whole blood heparin concentrations do not correlate with plasma antifactor-Xa heparin concentrations in pediatric patients undergoing cardiopulmonary bypass. Perfusion. 2000;15:203-9.

30. Pekelharing J, Furck A, Banya W, Macrae D, Davidson SJ. Comparison between thromboelastography and conventional coagulation tests after cardiopulmonary bypass surgery in the paediatric intensive care unit. Int J Lab Hematol. 2014; 36:465-71.

31. Welsh KJ, Padilla A, Dasgupta A, Nguyen AN, Wahed A. Thromboelastography is a suboptimal test for determination of the underlying cause of bleeding associated with cardiopulmonary bypass and may not predict a hypercoagulable state. Am J Clin Pathol. 2014;142:492-7.

32. Finley A, Greenberg C. Review article: heparin sensitivity and resistance: management during cardiopulmonary bypass. Anesth Analg. 2013;116:1210-22.

33. Fischer R, Sachs UJ, Heidinger KS, Eisenburger D, Kemkes-Matthes B Prevalence of hereditary antithrombin mutations is higher than estimated in patients with thrombotic events. Blood Coag Fibrinol. 2013;24:444-8.

34. Badrin O, Kushairi S, Zakaria Z, Sachithanandan A. Successful anticoagulation with fresh frozen plasma for cardiopulmonary bypass in a patient with heparin resistance: a cautionary tale. Available at: http://www.ncbi.nlm.nih.gov/pmc/ articles/PMC3645014/. Accessed October 28, 2015.

35. Beattie GW, Jeffrey RR. Is there evidence that fresh frozen plasma is superior to antithrombin administration to treat heparin resistance in cardiac surgery? Interact Cardiovasc Thorac Surg. 2014;18:117-20.

36. Avidan MS, Levy JH, van Aken H, Feneck RO, Latimer RD, Ott E, et al. Recombinant human antithrombin III restores heparin responsiveness and decreases activation of coagulation in heparin-resistant patients during cardiopulmonary bypass. J Thorac Cardiovasc Surg. 2005;130:107-13.

37. Dietrich W, Busley R, Spannagl M, Braun S, Schuster T, Lison S. The influence of antithrombin substitution on heparin sensitivity and activation of hemostasis during coronary artery bypass graft surgery: a dose-finding study. Anesth Analg. 2013;116:1223-30.

38. Ranucci M, Baryshnikova E, Crapelli GB, Woodward MK, Paez A, Pelissero G Preoperative antithrombin supplementation in cardiac surgery: a randomized controlled trial. J Thorac Cardiovasc Surg. 2013;145:1393-9.

39. Kaltman JR, Andropoulos DB, Checchia PA, Gaynor JW, Hoffman TM, Laussen PC, et al. Report of the pediatric heart network and National Heart, Lung, and Blood Institute Working Group on the perioperative management of congenital heart disease. Circulation. 2010;121:2766-72.

Key Words: congenital heart disease, surgery, thrombosis, heparin, antithrombin 